\title{
The seeded crystallization of $\beta L$-glutamic acid in a continuous oscillatory baffled crystallizer
}

Naomi E. B. Briggs,,${ }^{\dagger}$ Ulrich Schacht,${ }^{\star}$ Vishal Raval,${ }^{\dagger}$ Thomas McGlone, ${ }^{\dagger}$ Jan Sefcik, ${ }^{\star}$ and Alastair J. Florence* ${ }^{*}$

${ }^{\dagger}$ EPSRC Centre for Innovative Manufacturing in Continuous Manufacturing and Crystallisation c/o Strathclyde Institute of Pharmacy and Biomedical Sciences, University of Strathclyde, Technology and Innovation Centre, 99 George Street, Glasgow, G1 1RD, United Kingdom

${ }^{*}$ EPSRC Centre for Innovative Manufacturing in Continuous Manufacturing and Crystallisation c/o Department of Chemical and Process Engineering, University of Strathclyde, 75 Montrose Street, Glasgow G1 1XJ, UK

\section{KEYWORDS}

L-glutamic acid, continuous crystallization, continuous oscillatory baffled crystallizer, polymorphism, seeding

\section{ABSTRACT}

A continuously seeded $L$-glutamic acid cooling crystallization process, in a continuous oscillatory baffled crystallizer, was designed and operated to deliver control over polymorphic 
form. Different feed solution concentrations and seed loadings of $\beta L$-glutamic acid crystals were examined. Steady-state operation, based on particle size distribution and polymorphic form, was demonstrated consistently after two residence times. Where bulk supersaturation remained in the range $2-3$, polymorphic phase purity of the thermodynamically stable $\beta$ polymorph was retained. However, when bulk supersaturation exceeded this range to values of $3-8$, primary nucleation of the metastable $\alpha$ polymorph was observed and product crystals were a mixed phase. In the absence of seeding the system could not be operated without significant encrustation to the vessel surface thus leading to loss of control, whereas a continuously seeded approach allowed robust processing for at least $10 \mathrm{~h}$.

TOC
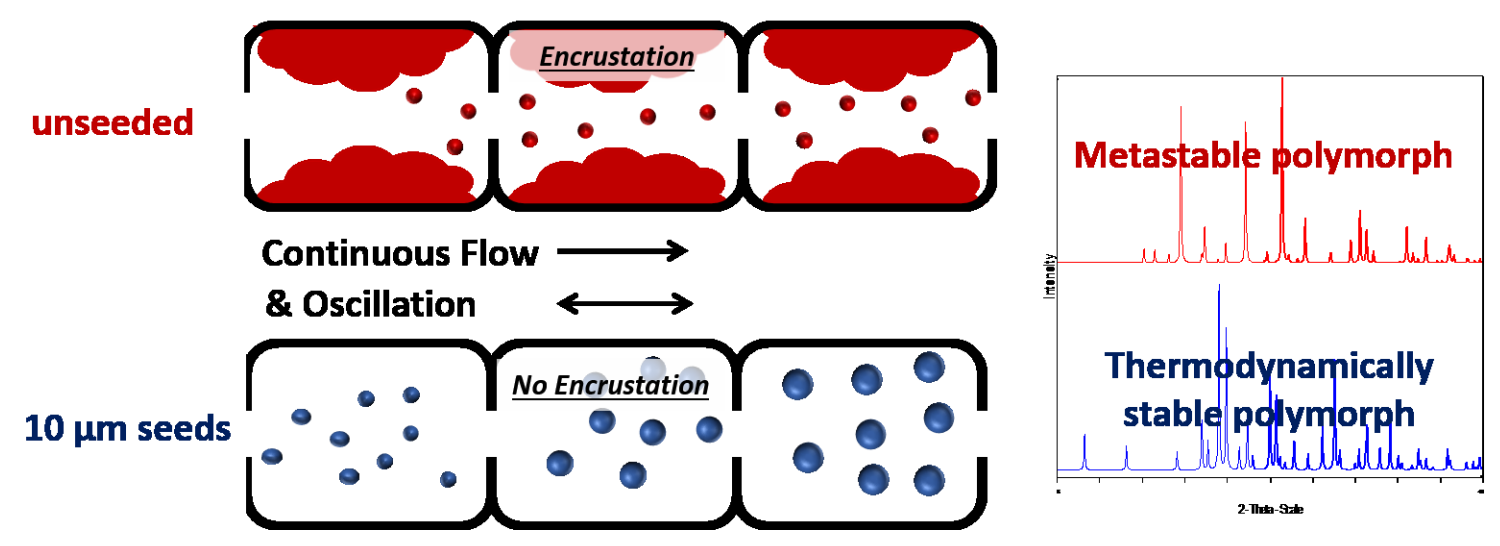

\section{INTRODUCTION}

Limitations in fully characterizing the physical transformations involved in crystallization often relate to the challenges in measuring the formation of crystal nuclei and their subsequent growth. In addition, many organic materials are polymorphic ${ }^{1,2}$ and adopt chemically identical solid forms possessing different physiochemical properties including solubility and stability, as well as particle properties, such as particle size distribution (PSD) and morphology, potentially influencing bio- 
availability and downstream processability. Thus the control of polymorph formation, subsequent growth and possible transformations, is a fundamental requirement for development of robust pharmaceutical crystallization processes.,

The pharmaceutical industry has traditionally relied upon batch methods for crystallization and the production of active pharmaceutical ingredients (APIs). However, drivers to produce higher quality materials with less batch-to-batch variability and more efficient equipment are increasingly becoming a priority. ${ }^{5}$ As a consequence, the continuous manufacturing of pharmaceuticals has received much interest across industry, academia and regulatory communities. ${ }^{6-11}$

Oscillatory flow systems have drawn recent attention within the continuous manufacturing and crystallization community. ${ }^{12}$ A continuous oscillatory baffled crystallizer (COBC) is a type of plug-flow reactor (PFR) which allows continuous cooling crystallization, moving solutions and/or suspensions through a series of periodically spaced orifice baffled tubes. The application of oscillatory flow results in the formation of eddies between the baffles ${ }^{13}$ providing efficient mixing regions and near-plug flow operation. ${ }^{12,14,15}$ The improved uniformity of the internal environment with respect to distributions of shear rates, temperature gradients and mass transfer, ${ }^{16,17}$ combined with the decoupling of mixing and net flow, ${ }^{18}$ provides the potential for effective operation and scaling of laboratory pharmaceutical crystallization processes to industrial-sized processes. ${ }^{19} \mathrm{Of}$ particular attraction, the ability to extend the mean residence time, under plug-flow conditions, at a similar mixing intensity, ${ }^{20}$ is advantageous to slow processes such as crystallization where longer residence times are needed for the induction of nucleation and the subsequent growth of crystals, in addition to a uniform mixing environment facilitating uniform crystal growth. 
Continuous oscillatory flow may be described using three dimensionless numbers; $R e_{0}$, the oscillatory Reynolds number, $S t$, the Strouhal number and $R e_{\mathrm{n}}$, the net flow Reynolds number. ${ }^{21}$ $R e_{\mathrm{o}}$ describes the intensity of oscillatory mixing applied within the tube. $S t$ is the ratio of the tube diameter to the oscillation amplitude and a measure of the eddy propagation inside each interbaffle zone. The definition of amplitude is the distance between the minimum and maximum displacement of fluid within the tube as a function of the applied oscillation. In the literature, half this distance is usually reported i.e. center-to-peak as opposed to peak-to-peak and given the symbol $\chi_{o} . R e_{\mathrm{n}}$ is a descriptor based on the net flow. These are governed by the following equations:

$$
\begin{aligned}
& R e_{\mathrm{o}}=\frac{2 \pi f \chi_{o} \rho d}{\mu} \\
& S t=\frac{d}{4 \pi \chi_{o}} \\
& R e_{\mathrm{n}}=\frac{\rho u d}{\mu}
\end{aligned}
$$

$d=$ internal tube diameter $(\mathrm{m}), \chi_{o}=$ center-to-peak amplitude $(\mathrm{m}), f=$ frequency $(\mathrm{Hz}), \rho=$ density $\left(\mathrm{kgm}^{-3}\right), \mu=$ fluid viscosity $\left(\mathrm{kgm}^{-1} \mathrm{~s}^{-1}\right)$, and $u=$ mean velocity $\left(\mathrm{ms}^{-1}\right)$. Flow should be fully reversing (to maximize the mixing effect) and to achieve this $R e_{\mathrm{o}}$ should be $>R e_{\mathrm{n}}$. A velocity ratio, $\psi$, was proposed to relate the oscillatory velocity to the net flow velocity ${ }^{15}$ and is described by:

$$
\psi=\frac{R e_{0}}{R e_{\mathrm{n}}}
$$

Recommendations for oscillatory flow ${ }^{14,15,22-25}$ include operating with $R e_{\mathrm{o}} \geq 100, S t \leq 0.5, \operatorname{Re}_{\mathrm{n}}$ $\geq 50$, and velocity ratios between 2 and 10 . 
There have been limited studies of crystallization within continuous oscillatory flow; to date the majority of oscillatory baffled flow crystallizations have been completed in batch mode. Reports using a batch oscillatory baffled crystallizer (OBC) include investigations with paracetamol, ${ }^{16,26,27}$ sodium chlorate ${ }^{28,29}$ and adipic acid. ${ }^{30}$ Batch OBCs have been designed to allow investigation of similar type mixing environments prior to continuous experimentation whilst minimizing consumption of material. ${ }^{12}$ Only two papers ${ }^{9,19}$ report a basic methodology towards continuous oscillatory crystallization where batch $\mathrm{OBC}$ crystallizations were carried out before continuous trials were completed. Specifically, $L$-glutamic acid (LGA) has been successfully crystallized in a batch OBC. ${ }^{31-33}$ However, neither the continuous crystallization of LGA operated in a COBC nor a suitable seeding strategy have been reported.

LGA can be classified as a drug-like material. ${ }^{34}$ It is present in many food products and plays an important role in many neurodegenerative diseases. ${ }^{35,36}$ LGA has two known polymorphs with distinct characteristic morphologies. They are monotropically related with $\alpha$-LGA having the higher solubility across the temperature range of interest in this work. ${ }^{37}$ Therefore LGA presents itself as an ideal candidate for investigating control of polymorphism. The metastable $\alpha$ form exhibits prismatic crystal morphology, whilst the thermodynamically stable $\beta$ form adopts a plate or needle-like shape.

Extensive studies around the batch crystallization of LGA cover many crystallization aspects including kinetic studies on nucleation and growth rates, ${ }^{38-41}$ polymorph control, ${ }^{42-44}$ supersaturation (SS, defined in the Materials and Methods Section) control, ${ }^{45-47}$ purity, ${ }^{48}$ population balance modeling (PBM), ${ }^{49,50}$ effects of additives ${ }^{51-53}$ and solution mediated polymorphic transformation. ${ }^{37,54,55}$ The numerous batch investigations of LGA typically focus on small scale stirred tank crystallizer (STC) platforms $(<1 \mathrm{~L})$ and span a range of crystallization 
types including reactive, cooling and anti-solvent. Scale dependence has been reported ${ }^{56,57}$ where comparisons were made between operating in an STC at a scale of $c a .0 .5 \mathrm{~L}$ up to $20 \mathrm{~L}$, illustrating the need to understand the impact of vessel hydrodynamics at various scales on the crystallization process. Furthermore process analytical technology (PAT) coupled with a control system has been utilized to develop an industrial pilot scale $(250 \mathrm{~L})$ batch crystallization process for the production of $\beta$-LGA. ${ }^{58}$

However, there are only few reports illustrating continuous crystallization of LGA. Grier et al. patented a process generating the metastable $\alpha$ form using a continuous stirred tank reactor in $1968 .^{59}$ Here a feed stock was supplied as the aqueous LGA growth solution to a 4 L STC containing $\alpha$-LGA seeds and continuously pumping slurry to a second STC for further crystallization before a latter isolation stage. The process covered a residence time (RT) of $c a .2$ $\mathrm{h}$, and temperature ranges from $0-25{ }^{\circ} \mathrm{C}$. Roelands et al. described a continuous reactive crystallization of LGA using sodium glutamate and dilute sulfuric acid. ${ }^{60}$ The two solutions were continuously mixed in a Y-mixer, in order to create high SSs ranging from $4-22$ and complete mixing, before transfer to a collection vessel where the solution experienced post-mixing or quiescent conditions. When no post-mixing was applied the resulting polymorphic form was consistently the stable $\beta$ form. However, post-mixing treatments to the solutions favored the production of $\alpha$-LGA. A continuous anti-solvent crystallization process producing the stable $\beta$ form was reported by Myerson et al. ${ }^{61}$ In this study a $300 \mathrm{~mL}, 2.4 \mathrm{~m}$, PFR with Kenics ${ }^{\circledR}$ type static mixers was utilized. Acetone was added as an anti-solvent to the aqueous LGA solution at multiple positions along the reactor length and the effects of anti-solvent addition on the resulting chord length distributions were discussed. The RT for this study was $c a .2$ min, experiments were 
conducted at $25^{\circ} \mathrm{C}$ and the process was operated for 7 residence times producing $\beta$-LGA with no observations of the metastable $\alpha$ form reported.

More recently a mixed suspension mixed product removal (MSMPR) set-up was used to study the aqueous continuous cooling crystallization of LGA. ${ }^{62}$ A $300 \mathrm{~mL}$ STC was operated with periodic addition and withdrawal of growth solution and slurry product respectively, and operation time scales were reported to be up to $6 \mathrm{~d}$. Here, both seeded and unseeded methodologies were studied. During unseeded crystallization both polymorphs were produced in pure phase, $\alpha$-LGA using a crystallization procedure at $25^{\circ} \mathrm{C}$ and $\beta$-LGA at $45^{\circ} \mathrm{C}$. This work illustrated challenges in producing the stable $\beta$ form during continuous operation. Due to the higher growth rate of $\alpha$-LGA when compared to the $\beta$ form, it was concluded if $\alpha$ nucleates in the presence of $\beta$, a polymorphic switch occurs during continuous operation, similar to conclusions drawn from the aforementioned continuous reactive crystallization of LGA ${ }^{60}$ This study ${ }^{62}$ also suggests that seeded approaches at steady state continuous operation may not be sufficient to control polymorphism within an MSMPR.

Although there have been several crystallization studies in oscillatory flow platforms and numerous investigations on the crystallization behavior of LGA, the continuous crystallization of pharmaceutically relevant materials is not well documented. In addition to this, the application of continuous oscillatory flow for pharmaceutical crystallization is substantially limited and seeding strategies in a COBC have not been previously reported. Moreover, control of polymorphic forms of LGA in a COBC has not been successfully achieved. Herein, we report the development of a continuously seeded, cooling crystallization process resulting in polymorphic phase pure LGA in a COBC. 


\section{MATERIALS AND METHODS}

Materials. $\beta$-LGA (purity $\geq 98.5 \%$, CAS 56-86-0, FCC) containing $\leq 0.1 \%$ of the $\alpha$ form was purchased from Sigma Aldrich, Germany. De-ionized water was sourced on-site from a Thermo Scientific Barnstead RO water purification unit. Experiments were performed in an air conditioned laboratory at $20 \pm 2{ }^{\circ} \mathrm{C}$.

Equipment. Seeded crystallizations of LGA were performed in a $15 \mathrm{~mm}$ internal diameter COBC mounted horizontally, the set-up consisted of 32 jacked glass tubes (straights) and 8 nonjacked glass bends. The geometry of the COBC is shown in Figure 1. Cooling water was circulated through the jackets in a counter current manner by heater/chillers (HCs) (Lauda Eco RE 630S). Peristaltic pumps (Watson-Marlow 520S) supplied the COBC with growth solution and seed suspension stored in two independently heated feed tanks. The temperature of the second COBC glass straight (S2) and the seed suspension were controlled by the same HC to maintain the solution at a SS of approximately 1 . Thermocouples, 24 in total, were used to record the cooling profile of thirteen temperature zones, each zone controlled by $1 \mathrm{HC}$, zones are shown in color in Figure 2. Fluid oscillation was provided by a fluid filled bellows unit controlled by custom electronics (housed in a control box). Before tube lines were changed over to supply the feedstock and seeds, both the $\mathrm{COBC}$ and the bellows unit were flushed with water using peristaltic pumps. During crystallization, slurries were collected at the outlet. The main feed growth solution was prepared at two concentrations, and the seed suspension prepared at two seed loadings. The total length and volume of the system were $25 \mathrm{~m}$ and $5.1 \mathrm{~L}$ respectively, however as the seeding port was located between straights 2 and 3, 30 straights and 8 bends were used for growth. The operating conditions are summarized in Table 1. 

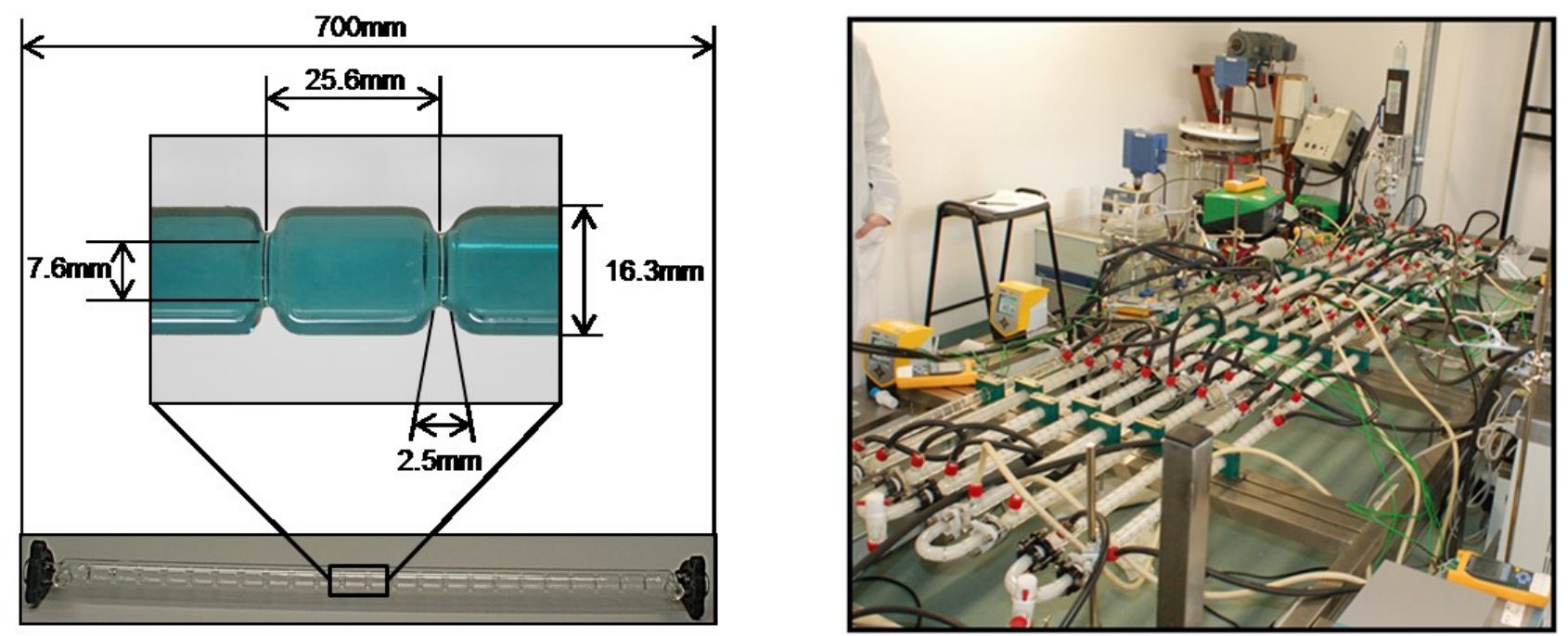

Figure 1. COBC geometry and set-up for seeded experiments. Photograph of a single glass COBC straight (left), inset shows a magnified image of a single inter-baffle zone, with dimensions indicated and a photograph of the COBC set-up (right) used for seeded COBC experiments.

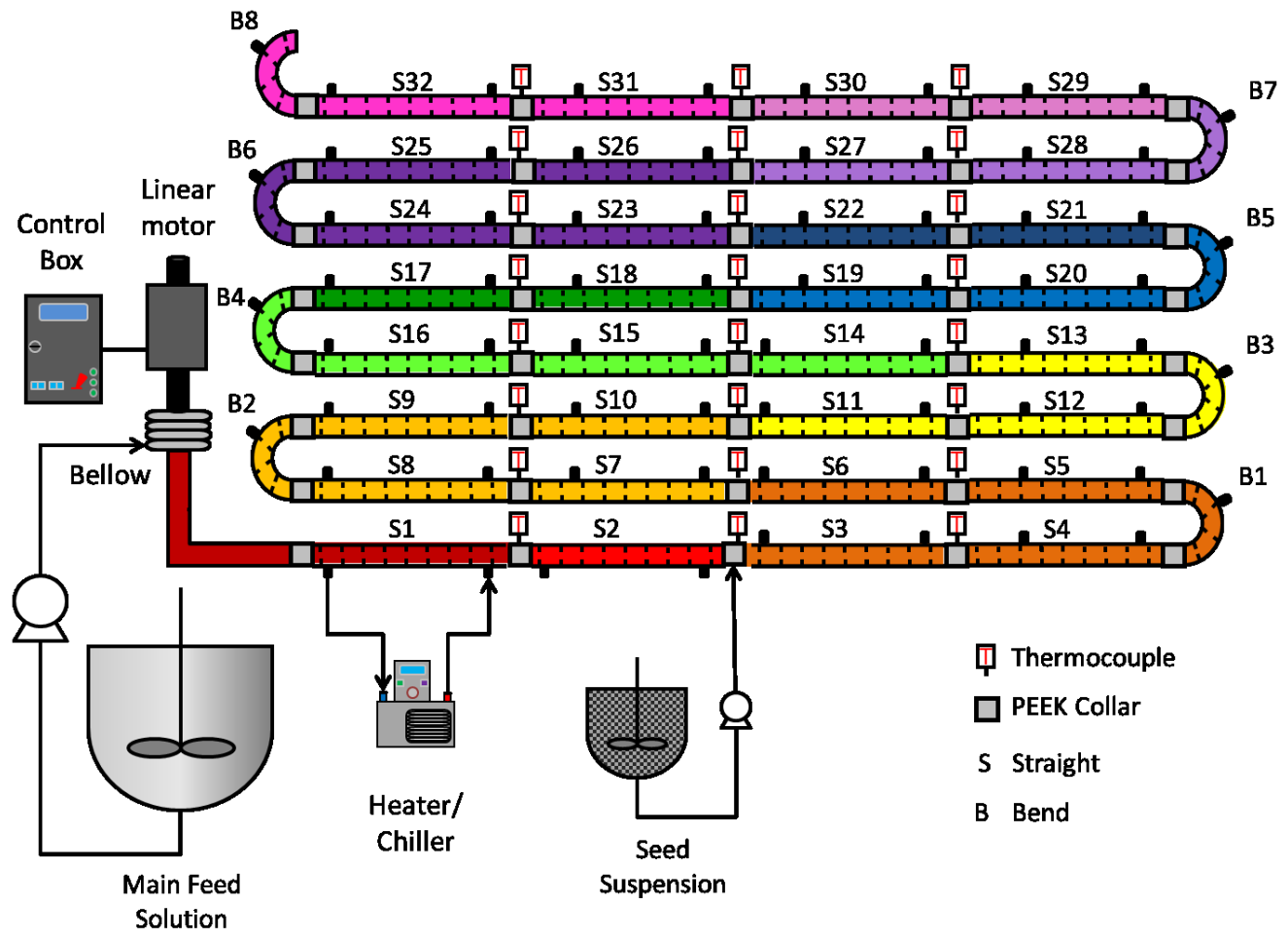

Figure 2. COBC set-up for seeded crystallizations. Schematic of the seeded COBC crystallization platform. Thermocouple positions are shown, and the 13 temperature zones are 
indicated by colors (zone $1 \mathrm{~S} 1$, zone $2 \mathrm{~S} 2$, zone $3 \mathrm{~S} 3-\mathrm{S} 6$, zone $4 \mathrm{~S} 7-\mathrm{S} 10$, zone $5 \mathrm{~S} 11$-S13, zone 6 S14-S16, zone 7 S17-S18, zone 8 S19-S20, zone 9 S21-S22, zone 10 S23-S26, zone 11 S27S28, zone 12 S29-S30 and zone 13 S31-S32).

Table 1: COBC seeded crystallization operating parameters

\begin{tabular}{cccccccc}
\hline $\begin{array}{c}\text { Frequency } \\
(\mathrm{Hz})\end{array}$ & $\begin{array}{c}\text { Amplitude } \\
(\mathrm{mm})\end{array}$ & $\begin{array}{c}\text { Main flow } \\
(\mathrm{g} / \mathrm{min})\end{array}$ & $\begin{array}{c}\text { Seed flow } \\
(\mathrm{g} / \mathrm{min})\end{array}$ & $\mathrm{Re}_{\mathrm{n}}$ & $\mathrm{Re}_{\mathrm{o}}$ & $\Psi$ & $\mathrm{St}$ \\
\hline 1 & 30 & 30 & 20 & 70 & 1400 & 20 & 0.008 \\
\hline
\end{tabular}

Analytics. Solid materials were characterized off-line via x-ray powder diffraction (XRPD). XRPD fingerprinting was performed on $c a .50 \mathrm{mg}$ of sample placed in a 28 well plate, supported by Kapton film (7.5 $\mu \mathrm{m}$ thickness). Data was collected on a Bruker AXS D 8 Advance transmission diffractometer equipped with $\theta / \theta$ geometry, primary monochromatic radiation $\left(\mathrm{Cu} \mathrm{K} \alpha_{1} \lambda=\right.$ $1.54056 \AA$ ), a Braun 1D position sensitive detector and an automated multi-position x-y sample stage. Data was collected from $4-35^{\circ} 2 \theta$ with a $0.015^{\circ} 2 \theta$ step size and $1 \mathrm{~s} \mathrm{step}^{-1}$ count time. XRPD powder patterns were compared with known standards using Bruker-AXE software Eva 2 or a Pawley-type fit made to the data with the known unit cell parameters ${ }^{63,64}$ using Dash 3.3.2.

Optical images were acquired using a Motic B1 series microscope equipped with 4x, 10x, 40x and 100x magnification objective lenses. Images were visualized using Motic Images 2.0 software.

PSDs were obtained by laser diffraction measurements, using a Mastersizer 2000 (Malvern Instruments). Slurries were dispersed in a saturated solution (LGA and water) using a Hydro 2000SM dispersion unit. Slurry was added to the dispersion until the laser obscuration reached 6 $\%$. Five measurements were averaged for each sample.

\section{Supersaturation (SS).}

Throughout this manuscript, SS values are expressed in terms of the SS ratio $(S)$ defined by: 


$$
S=\frac{C}{C^{*}}
$$

$\mathrm{C}=$ solution concentration and $\mathrm{C}^{*}=$ equilibrium solution concentration (at a constant temperature and pressure).

Sample preparation. For LGA samples, solid slurries where removed, immediately filtered (Millipore $0.45 \mu \mathrm{m}$ papers) and washed before drying in an oven at $40{ }^{\circ} \mathrm{C}$ until constant mass.

Seed preparation. Seeds were prepared using a turbulent jet reverse anti-solvent process, (see Electronic Supporting Information, ESI). Using this method, $\beta$-LGA seeds with a mean size $c a .10$ $\mu \mathrm{m}$ were produced.
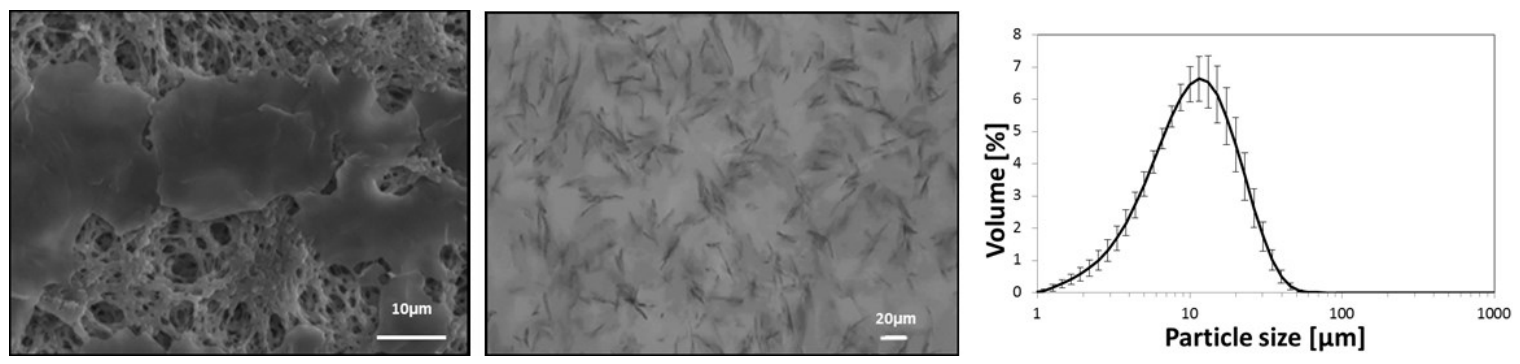

Figure 3. Seed Crystals used for the crystallization of LGA in a COBC. SEM image (left), optical microscope image (middle) and PSD (right) of LGA seed crystals. The seed obtained from the continuous anti-solvent process display a flake like morphology.

Operating conditions. Four continuously seeded $\mathrm{COBC}$ experiments were carried out (Table 2) comprising a basic design with a high and low feed solution concentration and a high and low seed mass loading. This design space was used to assess control over crystal growth and polymorphic form during continuous crystallization. $\mathrm{COBC}$ operating conditions were selected to ensure a sufficient RT was available for particle growth ( $c a .80$ minutes) alongside the operation within a near plug-flow domain. It should be noted that we have performed a full residence time distribution (RTD) study on the COBC configuration described herein highlighting axial 
dispersion values below those stated in literature defining plug-flow operation ${ }^{65}$ which we intend to publish elsewhere.

Table 2: Experimental conditions used for seeded COBC experiments.

\begin{tabular}{ccc}
\hline & \multicolumn{2}{c}{$\begin{array}{c}\text { Feed solution concentration } \\
\left(\mathrm{g} / \mathrm{kg}_{\text {(solution) }}\right)\end{array}$} \\
\cline { 2 - 3 } $\begin{array}{c}\text { Seed mass } \\
\text { loading }\end{array}$ & $\begin{array}{c}\text { High } \\
40 \mathrm{~g} / \mathrm{kg}\end{array}$ & $\begin{array}{c}\text { Low } \\
18 \mathrm{~g} / \mathrm{kg}\end{array}$ \\
\hline $\begin{array}{c}\text { High } \\
0.4(\mathrm{~g} / \mathrm{kg})\end{array}$ & Expt. 1 & Expt. 2 \\
$\mathbf{L o w}$ & Expt. 3 & Expt. 4 \\
$0.1(\mathrm{~g} / \mathrm{kg})$ & & \\
\hline
\end{tabular}

\section{RESULTS AND DISCUSSION}

Continuous unseeded experiments. A number of unseeded crystallizations were carried out using a similar set-up to Figure 2 but without using a seeding suspension vessel (see ESI). Crystallizations were completed over a range of concentrations, cooling profiles, oscillatory conditions and flow rates $\left(20-45 \mathrm{~g} / \mathrm{kg}, 0.3-3{ }^{\circ} \mathrm{C} / \mathrm{min}, 1-2 \mathrm{~Hz}, 20-30 \mathrm{~mm}, 20-120 \mathrm{~g} / \mathrm{min}\right.$, respectively). Under all conditions investigated where primary nucleation was induced, encrustation of the glass surface was dominant and subsequent crystal growth on the glass walls led to numerous detrimental effects including loss of control of PSD, blockages and ultimately process shut down.

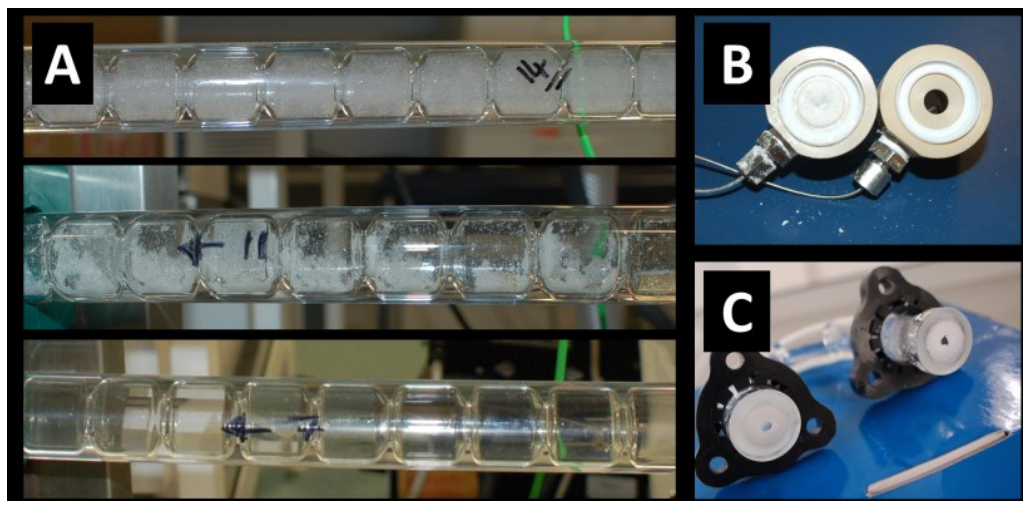


Figure 4: Encrustation and blockages during unseeded crystallization in a COBC. Photograph A (left) shows COBC glass straights during operation: a clear solution prior to nucleation (7), severe encrustation (11) and encrusted walls with a dense suspension of crystalline material flowing through (14). Photographs (B and C, right) show dismantled equipment after an unseeded COBC run. Polyether ether ketone (PEEK) collars (B) with a complete blockage (left) in comparison to a clean collar (right) and a partial blockage and restriction of a COBC bend (C).

Encrustation during unseeded crystallizations prevented a comprehensive study of nucleation kinetics and process development of LGA in the COBC. In general, encrustation presents a severe risk in continuous crystallization processes and if not properly managed prevents operation for extended periods. Uncontrolled accumulation of material on vessel walls can disrupt heat transfer, alter SS, lead to increases in back pressure, vary oscillatory conditions, affect particle size, lead to non-steady state operation and in many cases cause process failure. These issues highlight the need to ensure adequate control of SS throughout the crystallization process in order to ensure sufficient crystal growth, minimize undesired nucleation and prevent attachment of crystals at the vessel surface.

Encrustation of crystallization vessel surfaces during the crystallization of LGA has not been reported extensively. In the aforementioned MSMPR study, ${ }^{62}$ the unseeded continuous crystallization of LGA could be carried out for up to 45 hours ( 45 residence times) without reports of encrustation. However, some reports on STC investigations make reference to difficulties in obtaining reliable information from PAT due to fouling of probes during unseeded crystallizations $^{56}$ as well as reference to impeller shafts accumulating LGA encrusted material. ${ }^{57}$ The COBC has a surface area per unit volume over one order of magnitude higher than an equivalent volume STC (see ESI). Therefore a higher extent of local SS close to the surface during cooling operation can potentially increase the likelihood of encrustation, particularly over extended periods of operation. Encrustation challenges have been described in the literature ${ }^{66,67}$ 
and mitigation and control strategies include seeding,${ }^{68}$ ultrasound ${ }^{69}$ and dynamic modelling within flow. ${ }^{70}$

In over 30 continuous unseeded crystallization experiments, the COBC exclusively produced the metastable $\alpha$ phase. In a small number of these unseeded studies trace amounts of the $\beta$ form were observed. This is in contrast to reported batch $\mathrm{OBC}$ experiments under similar operating conditions $^{31-33}$ where no surface encrustation was reported and polymorph selectivity could be achieved. For the work presented here, the approach used eliminates the need for primary nucleation under high SS within the COBC through the use of continuous seeding using seeds produced from a continuous anti-solvent process (details in ESI).

Continuous seeded crystallization experiments. Seeded crystallization involving controlled growth of particles can be operated at relatively low SS. This should therefore reduce the potential for encrustation within the $\mathrm{COBC}$ as the need to drive the system to high SS to induce primary nucleation is eliminated and indeed this is a common strategy used to control crystallization kinetics as well as polymorphic form. ${ }^{43,71-73}$ The seeding strategy provides a predetermined number of seeds of the desired form and size into the supersaturated primary feed solution for controlled growth. The seeding approach was developed from a series of small scale studies in which seed loadings and temperatures profiles were investigated. ${ }^{71,74}$ The selected conditions which gave acceptable control over growth rate and polymorphic form are shown in Table 2. Four seeded continuous crystallization experiments were carried out to investigate the product particle properties (size and polymorphic form) and operating conditions for continuously seeded $\beta$-LGA crystallization (Table 2). Figure 5 shows the measured temperature profiles used during each of the continuously seeded continuous crystallization experiments. 


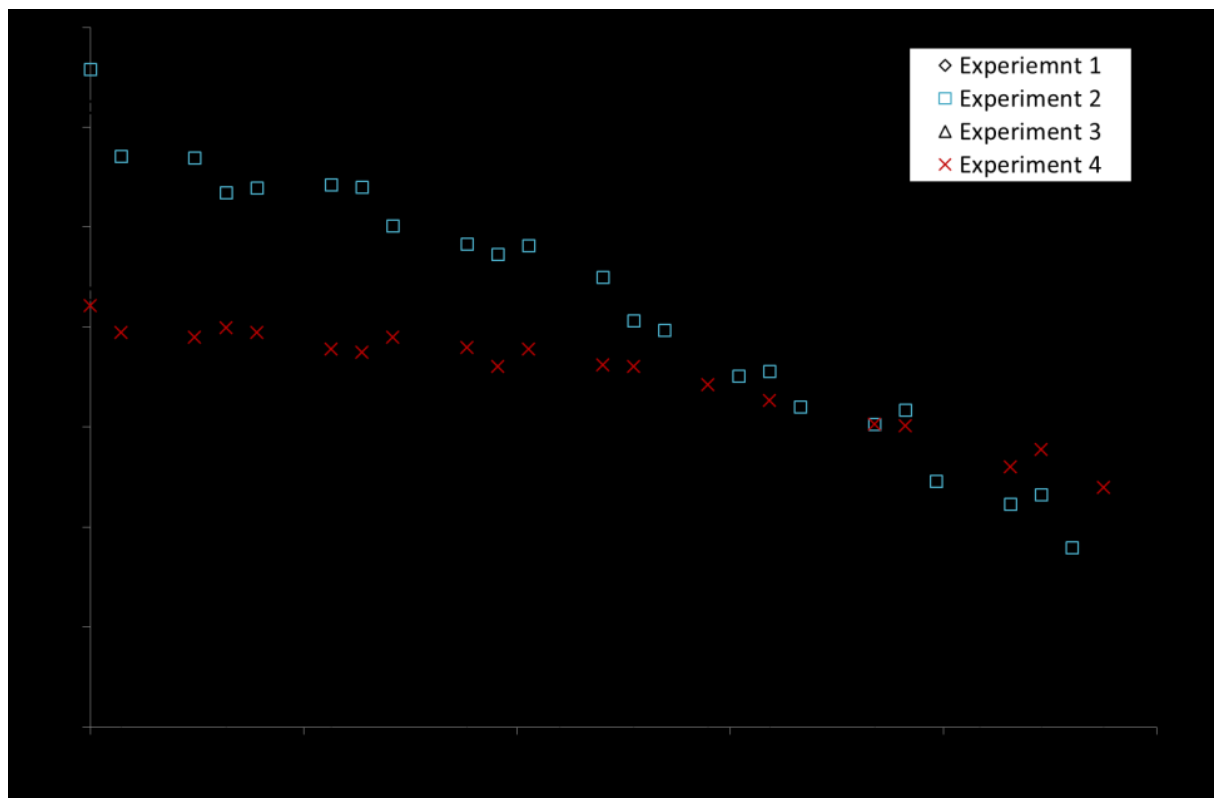

Figure 5 Cooling profiles for seeded LGA COBC experiments. Plot showing measured temperatures during seeded COBC crystallisations. Temperature zones (Figure 2) are indicated e.g. zone 3 (Z3), zone 4 (Z4) etc.

Crystal growth and polymorphism. Over the four COBC experiments completed (Table 2) crystal growth and polymorphic purity were assessed. Figure 6 shows the final resulting product PSDs and Table 3 shows the resulting mean particle sizes. When a seeding methodology is used to control crystal growth without the formation of new nuclei, the conservation of seed number can be presumed with the assumption that no agglomeration occurs. In this scenario the mass balance can be expressed as follows: ${ }^{.75}$

$$
\frac{W_{s}+Y_{t}}{W_{s}}=\left(\frac{L_{s p}}{L_{s}}\right)^{3}
$$

$W_{s}=$ mass of seeds, $Y_{t}=$ mass of dissolved solute forming crystals, $L_{s p}=$ product crystal size, $L_{s}=$ size of seed crystals. Thus, as expected from the mass balance, lower feed solution concentrations (experiments 2 and 4) yielded smaller mean crystal size (ca.90 $\mu \mathrm{m}$ and $c a .70 \mu \mathrm{m})$ 
than higher feed solution concentrations ( 1 and 3; mean crystal sizes $c a .240 \mu \mathrm{m}$ and $c a .320 \mu \mathrm{m}$ were observed). Similarly, the effect of seed loading follows the expectation where a high seed loading (experiment 1) leads to a smaller size, as compared to a low seed loading (experiment 3 ) leading to a larger size. However the seed loading effect with a low feed solution concentration deviates from expectation with the larger seed loading (experiment 2) producing a mean size of ca. $20 \mu \mathrm{m}$ larger than the lower seed loading (experiment 4). It is worth keeping in mind however that the nature of Mastersizer measurements and the fairly high extent of agglomeration in the system will have had an impact on these values. Notably, the combination of lower seed loading with high concentration led to the occurrence of encrustation in the system accompanied by primary nucleation of $\alpha$-LGA. This is as a consequence of loss of control over SS during the process (experiment 3). It is also worth noting that all PSDs show the presence of fines which suggests a small amount of primary/secondary nucleation and/or some crystal breakage during operation.

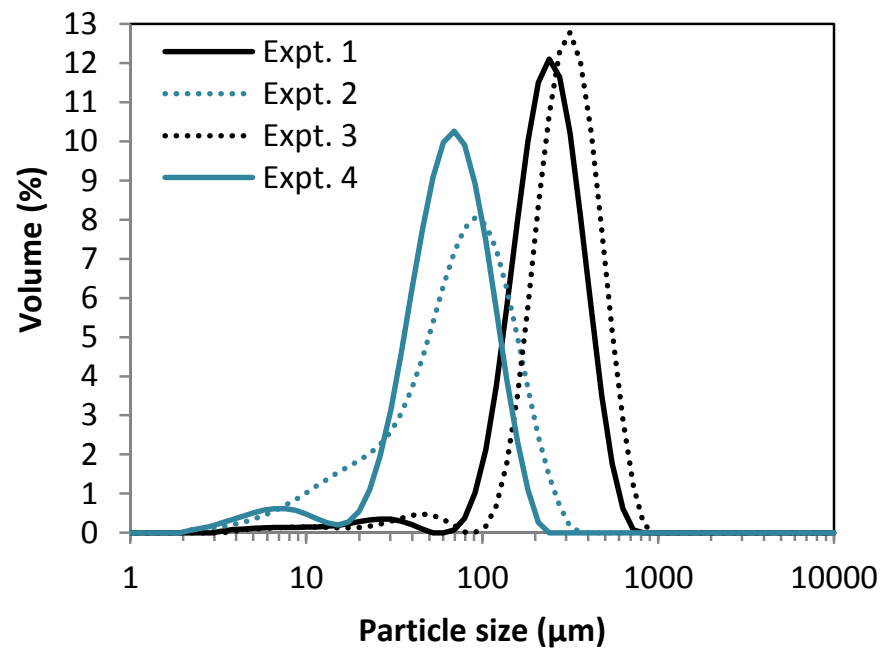


Figure 6: PSDs from seeded LGA crystallizations in the COBC. Plot showing the PSDs from experiments 1, 2, 3 and 4 (Table 2). The mean particle sizes were 240, 90, 320 and $70 \mu \mathrm{m}$ respectively.

Table 3: Mean particle size from seeded LGA experiments in the COBC.

\begin{tabular}{ccc}
\hline Seed mass & \multicolumn{2}{c}{ Feed solution concentration } \\
\cline { 2 - 3 } loading & High & Low \\
\hline High & Expt. 1 & Expt. 2 \\
& $\mathbf{2 4 0} \boldsymbol{\mu m}$ & $\mathbf{9 0} \boldsymbol{\mu m}$ \\
Low & Expt. 3 & Expt. 4 \\
& $\mathbf{3 2 0} \boldsymbol{\mu m}$ & $\mathbf{7 0} \boldsymbol{\mu m}$ \\
\hline
\end{tabular}

Product crystals collected from all experiments were agglomerates. Representative images of the product crystals from the seeded experiments are shown in Figure 7. The elongated plate morphology of the crystals within the agglomerate can be observed. Due to this agglomeration, the overall particle growth mechanism did not follow that of individual crystals therefore this posed challenges in drawing firm conclusions around the relationships between the impact of seeded loading and solution concentrations on crystal growth.
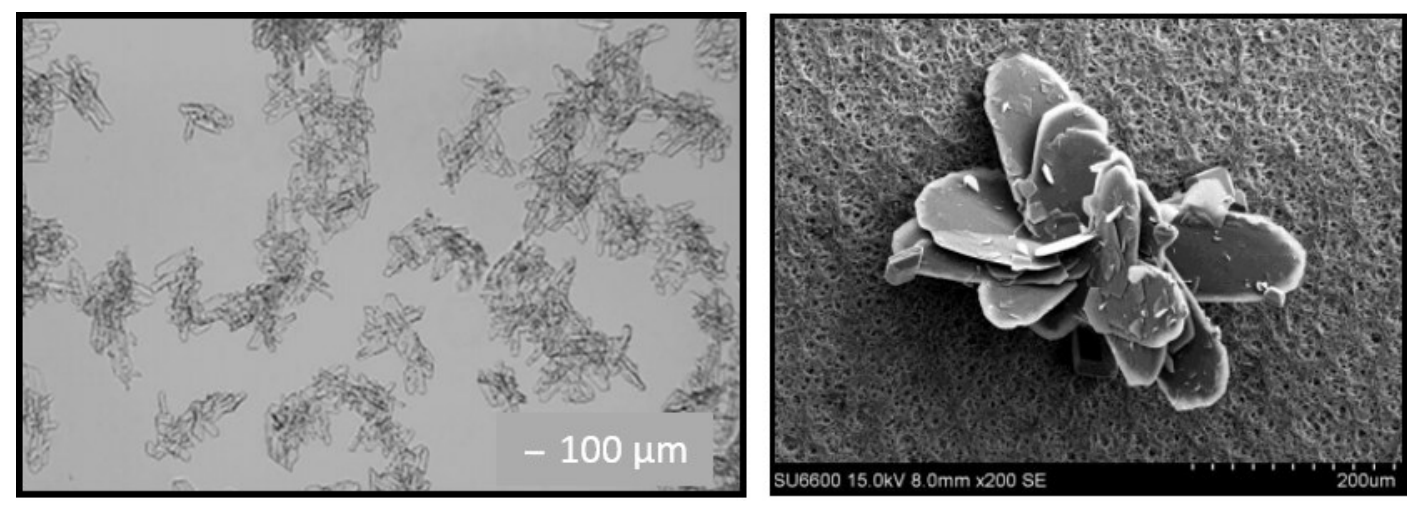

Figure 7 Images of crystal product from seeded crystallizations. Optical (left) and SEM (right) images of agglomerated product crystals (experiment 2, Table 2) obtained from a seeded COBC cooling crystallization process. 
The methodology here uses a simple mass balance based approach to deliver an initial design space. Current practice of crystallization process design and control include utilization of PBM to describe the relationship between process kinetics and product size distribution from first principles in addition to the application of model based feedback control strategies from PAT.,76${ }^{79}$ Further work to develop a PFR PBM which can also account for agglomeration is ongoing inhouse in addition to work developing a heat transfer model within the COBC to enable more accurate temperature control. Such capabilities will enable further process optimization based on first principles mechanistic understanding, however the current study highlights the ability to develop continuous crystallization processes capable of delivering consistent particle size whist avoiding encrustation and exploiting standard crystallization process design approaches.

Over each of the four continuously seeded experiments encrustation was not observed with the exception of experiment 3. Experiment 3 (high main feed concentration, low seed loading) was anticipated to generate the highest SS within the system. This fouled experiment was shut down after only 3 RTs due to substantial observed encrustation on the glass walls and the potential hazards associated with blockages alongside the danger of damaging equipment.

On examination of the product material using XRPD, experiment 3 alone was shown to contain the metastable $\alpha$ form. Figure 8 shows an overlay of product material from seeded experiments. Powder patterns of the pure $\alpha$ and $\beta$ (simulated from single crystal data) are also shown. These results illustrate that primary nucleation of the metastable form of LGA had occurred at some point within the COBC. Experiment 3 indicates exceeding SSs where growth and secondary nucleation of $\beta$-LGA is favorable, and moving into a domain where primary nucleation of $\alpha$-LGA is favorable, thus loss of process control over physical phase purity. 


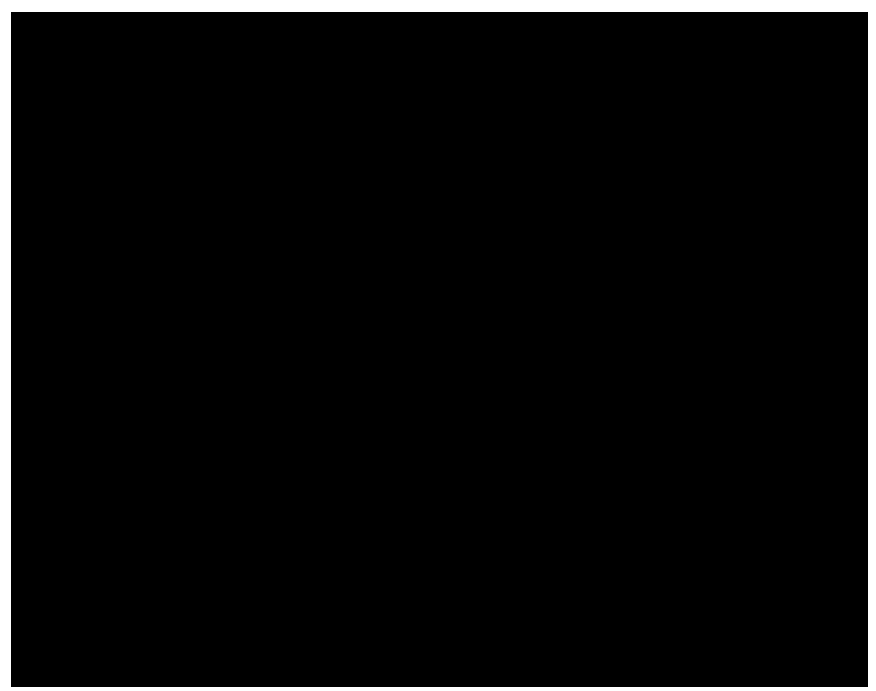

Figure 8: XRPD data from seeded continuous LGA crystallizations. Figure showing an overlay of product material from seeded experiments (Table 2), reference powder patterns of the pure alpha and beta (simulated from single crystal data) ${ }^{63,64}$ are also shown.

SS profiling. To measure SS values along the COBC, customized sampling bends (see ESI) were designed and positioned at bends 1, 2, 4, 6 and 7 for experiment 3. Slurry samples were extracted and rapidly filtered. Subsequently, solutions were evaporated and SSs were calculated after weighing the resulting crystal product using a mass balance. Figure 9 shows the calculated SS values from the mass balance of the extracted samples. Here a constant increase in SS along the $\mathrm{COBC}$ length can be observed during experiment 3. Final SS values from experiments 1, 2 and 4 (ranging from $c a .2-3$ ) are shown in addition to the starting SS at the seeding point. 


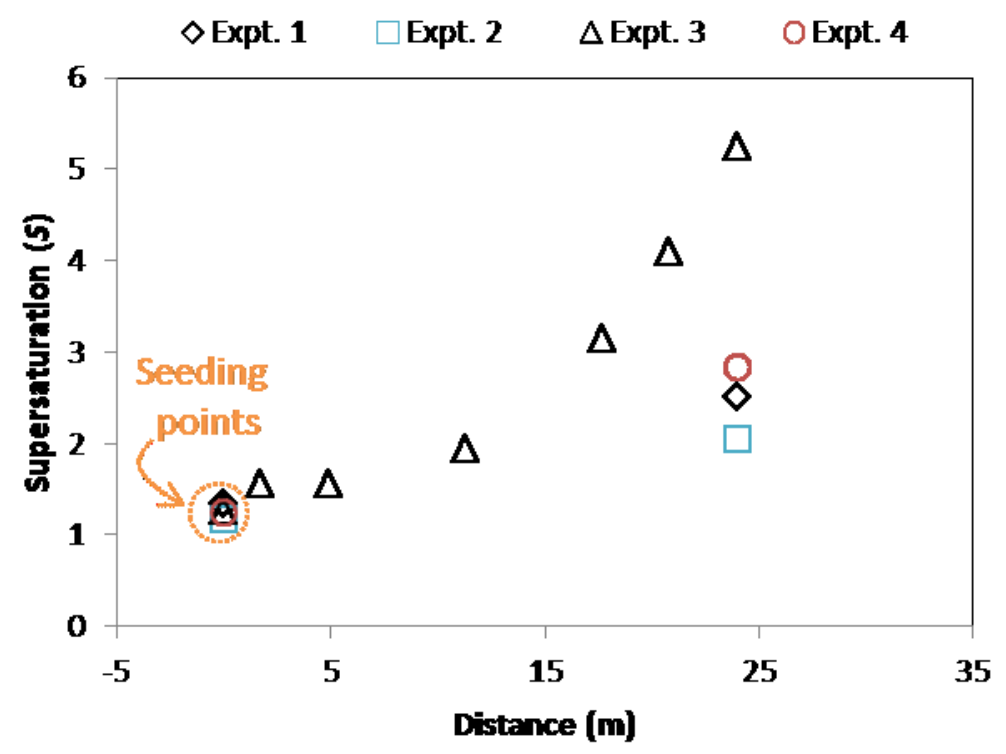

Figure 9: SS profile along the COBC. The graph illustrates the measured SS from manual samples illustrating a constant increase in bulk SS over the continuous crystallization process during experiment 3 (Table 2). Final SS values from experiments 1, 2 and 4 (ranging from ca. 2 3) are shown in addition to the starting $\mathrm{SS}$ at the seeding point.

The final SS values have been overlaid on the LGA phase diagram for reference in Figure 10. Using the smallest metastable boundary, proposed elsewhere for spontaneous nucleation of LGA from an aqueous system in batch oscillatory baffled flow conditions, ${ }^{31}$ it can be illustrated that when the bulk SS remains below this boundary the result is thermodynamically stable $\beta$ form. 


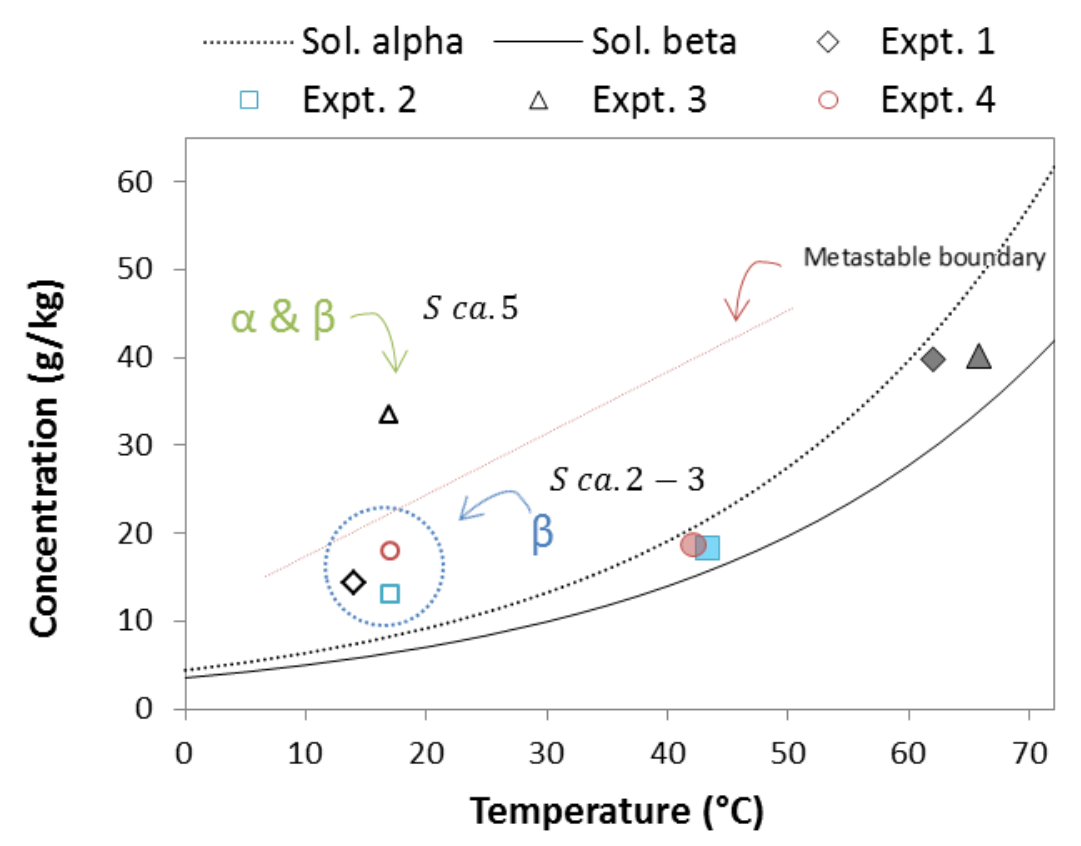

Figure 10: LGA crystallization diagram. Graph showing the temperature dependent solubility of LGA measured gravimetrically. ${ }^{80}$ Final measured SS values from continuous seeded experiments (open symbols) and initial seeding point concentrations (closed symbols) are shown in addition to the narrowest metastable boundary reported for spontaneous nucleation of LGA within oscillatory flow. ${ }^{31}$

Given the metastable zone width (MSZW) is a kinetic parameter dependent on many experimental considerations including concentration, agitation, temperature and volume, the boundary used in Figure 10 only serves as a guide. In reality the MSZW for continuous experiments should be assessed under the same operations conditions used within the seeded experiments. The results presented here indicate a MSZW somewhere between SS values of 3 - 5 and between these values primary nucleation of the metastable form, in the presence of $\beta$ crystals, is favorable. Further work is needed to define the maximum SS limit where the system can be operated controlling phase purity. However, this work begins to define successful regions for continuous operation. 
Steady state operation. During continuous processing, there is a period where parameters change before the system stabilizes. For a given process to fulfil its intended purpose the defined critical quality attributes (CQAs), e.g. desired polymorphic form, purity or PSD, should remain within the specified critical limits after this stabilization period and thus, steady state is reached. To maximize process efficiency, the time period between start-up and consistent production of material within specifications should ideally be minimized.

Efficient achievement of steady state may be assessed by investigation of CQAs with respect to time. Figure 11 shows representative examples of the change in PSD for each product sample, collected over several successive RTs, during unseeded and seeded continuous crystallizations. On comparison, it can be observed that a constant product PSD output is not obtained with unseeded crystallizations by the second RT and the product PSD moves from a uni-modal to a bi-modal distribution. However during seeded crystallizations, after the second RT the PSD remains consistent. The deviation from steady state in unseeded crystallizations can be explained as a consequence of uncontrolled crystallization and encrustation during operation. The unseeded product PSDs suggest secondary nucleation events, creating a shift in the PSD with respect to time. Furthermore, detachment of encrusted solids from the vessel walls during operation was observed and this results in an additional contribution to non-steady state product size distributions. Over a $10 \mathrm{~h}$ run time of seeded $\mathrm{COBC}$ crystallizations no visible signs of encrustation (during operation and cleaning) were observed when the SS levels were maintained in the range 2 - 3 and PSDs suggest controlled growth of the seed particles, with minimal fines, resulting in a consistent product PSD output. This steady state illustration of PSD with seeded experiments also highlights a robust process for PSD control of LGA. 

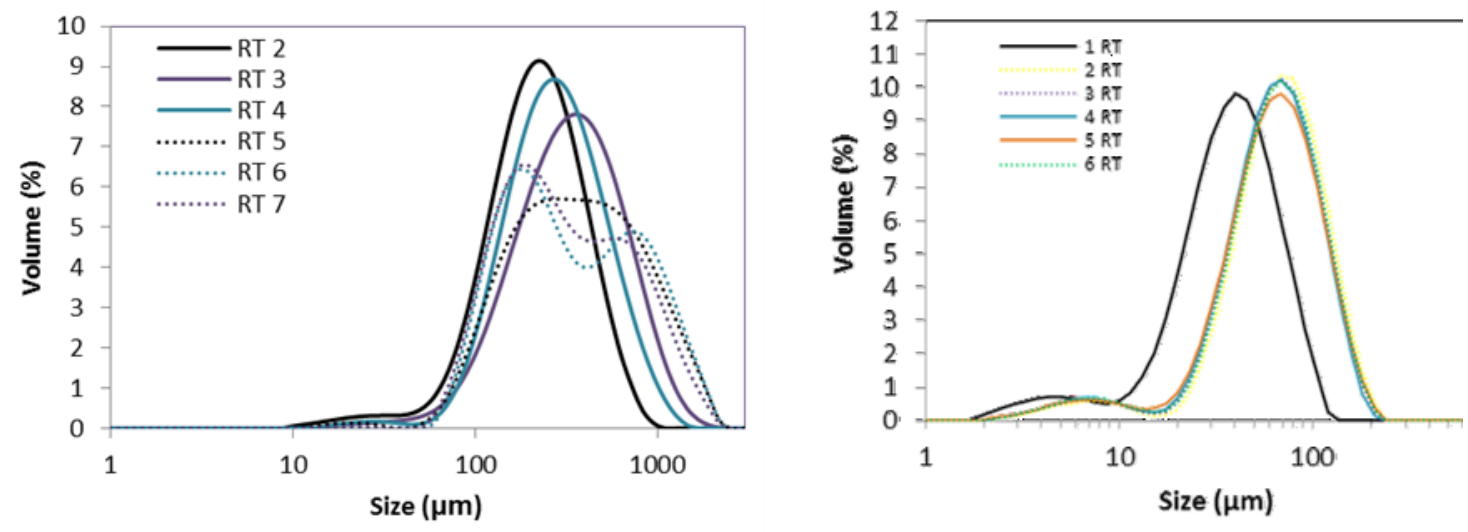

Figure 11: Evolution of PSDs during continuous crystallization. Graphs showing an overlay of 6 product sample PSDs collected from an unseeded (left) and continuously seeded (right) LGA COBC process.

Steady state after the second RT was obtained routinely when encrustation did not occur in the COBC. The previously mentioned unseeded PFR study ${ }^{61}$ was reported to reach steady state, with respect to the stable $\beta$ form, within the longer time of 4 - 10 RTs and operated for $14 \mathrm{~m}$, however this study relied on spontaneous nucleation and thus it would be anticipated that seeding would facilitate achieving steady state more quickly. The unseeded MSMPR investigations ${ }^{62}$ show selectivity over polymorphic form at various temperatures, the metastable form being isolated at lower temperature of $25^{\circ} \mathrm{C}$ after 2 RTs and the stable $\beta$ form at the high temperature of $45^{\circ} \mathrm{C}$. This is in contrast to the COBC unseeded experiments, where the metastable $\alpha$ form was isolated exclusively regardless of temperature. On comparison with other continuous platforms illustrating continuous production of LGA, the COBC, when seeded, requires a smaller number of RTs to reach steady state production of the stable $\beta$-polymorph. It should be mentioned however that it is difficult to compare these platforms directly. 
Conclusions. Throughout all unseeded continuous experiments, significant encrustation was observed and this could not be eliminated despite a multitude of changes to the operation and process conditions. For continuous LGA cooling crystallization it is advisable to avoid primary nucleation in the system although further work is needed around mitigating and possible control of encrustation. High SS coupled with a large surface area creates the potential of competitive deposition of material on the reactor walls. It is therefore recommended that for extended operation COBCs are well suited to lower SS operation with separation of high SS nucleation and low SS growth conditions although this is clearly system dependent.

When a seeded approach was taken, PSD and polymorphic steady state was reached by the second RT and operation for 8 RTs $(10 \mathrm{~h})$ was illustrated without encrustation or blockage of the system. Operation for longer periods of time was beyond the scope of this study. When the bulk solution SS remained within the range 2 - 3, encrustation was avoided. Seeding with $10 \mu \mathrm{m}$ crystals resulted in final particles with mean sizes ranging from $c a .70-320 \mu \mathrm{m}$ within a RT of $c a .80$ minutes allowing for the tailoring of crystal particle size. The need for continuous seeding also highlights the requirement for developing efficient strategies for the production of seeds and ideally an in-situ approach would be advantageous, eliminating the need for isolation and subsequent re-suspension.

\section{AUTHOR INFORMATION}

\section{Professor Alastair Florence}

*E-mail: alastair.florence@strath.ac.uk; Fax: +44 (0)141 552 2562; Tel: +44 (0)141 5484877

\section{Author Contributions}


The manuscript was written through contributions of all authors. All authors have given approval to the final version of the manuscript.

\section{Funding Sources}

We would like to acknowledge the Scottish Funding Council and EPSRC SPIRIT award for funding in addition to the EPSRC Centre for Innovative Manufacturing in Continuous Manufacturing and Crystallisation (EPSRC funding under grant reference: EP/I033459/1).

\section{SUPPORTING INFORMATION}

The Supporting Information is available free of charge on the ACS Publications website and includes further details on seed production, unseeded experiments, COBC surface area calculations and an illustration of the customised sample bends.

\section{ABBREVIATIONS}

LGA, L-Glutamic Acid; COBC, continuous oscillatory baffled crystallizer; HC, Heater/chiller; PSD, particle size distribution; XRPD, x-ray powder diffraction; API, active pharmaceutical ingredient; PFR, plug-flow reactor; OBC, oscillatory baffled crystallizer; RT, residence time; MSMPR, mixed suspension mixed product removal; STC, stirred tank crystallizer; PBM, population balance modeling; MSZW, metastable zone width; CQAs, critical quality attributes; PAT, process analytical technology; RTD, residence time distribution; SS, supersaturation; ESI, electronic supporting information.

\section{NOMENCLATURE}

d Internal tube diameter, $\mathrm{m}$

$\rho \quad$ Density $\left(\mathrm{kgm}^{-3}\right)$

f frequency $(\mathrm{Hz})$ 


$\begin{array}{ll}\chi_{o} & \text { centre-to-peak amplitude }(\mathrm{m}) \\ \mu & \text { viscosity }\left(\mathrm{kgm}^{-1} \mathrm{~s}^{-1}\right) \\ u & \text { mean velocity }\left(\mathrm{ms}^{-1}\right) \\ R e_{\mathrm{n}} & \text { net flow Reynolds number } \\ R e_{\mathrm{o}} & \text { oscillatory Reynolds number } \\ S t & \text { Strouhal number } \\ \psi & \text { velocity ratio } \\ W_{S} & \text { mass of seeds } \\ Y_{t} & \text { mass of dissolved solute forming crystals } \\ L_{S p} & \text { product crystal size } \\ L_{S} & \text { size of seed crystals } \\ S & \text { supersaturation ratio } \\ C & \text { solution concentration } \\ C^{*} & \text { equilibrium solution concentration }\end{array}$

\section{REFERENCES}

(1) Lu, J.; Rohani, S. Curr Med Chem 2009, 16, 884.

(2) Singhal, D.; Curatolo, W. Adv Drug Deliver Rev 2004, 56, 335.

(3) Fujiwara, M.; Nagy, Z. K.; Chew, J. W.; Braatz, R. D. J Process Contr 2005, 15, 493.

(4) Variankaval, N.; Cote, A. S.; Doherty, M. F. Aiche J 2008, 54, 1682.

(5) Badman, C.; Trout, B. L. J Pharm Sci 2015, 104, 779.

(6) Baxendale, I. R.; Braatz, R. D.; Hodnett, B. K.; Jensen, K. F.; Johnson, M. D.; Sharratt, P.; Sherlock, J. P.; Florence, A. J. J Pharm Sci 2014.

(7) Eder, R. J. P.; Schrank, S.; Besenhard, M. O.; Roblegg, E.; Gruber-Woelfler, H.; Khinast, J. G. Cryst Growth Des 2012, 12, 4733.

(8) Hou, G. Y.; Power, G.; Barrett, M.; Glennon, B.; Morris, G.; Zhao, Y. Cryst Growth Des 2014, 14, 1782.

(9) Lawton, S.; Steele, G.; Shering, P.; Zhao, L.; Laird, I.; Ni, X.-W. Org Process Res Dev 2009, 13, 1357.

(10) Mascia, S.; Heider, P. L.; Zhang, H. T.; Lakerveld, R.; Benyahia, B.; Barton, P. I.; Braatz, R. D.; Cooney, C. L.; Evans, J. M. B.; Jamison, T. F.; Jensen, K. F.; Myerson, A. S.; Trout, B. L. Angew Chem Int Ed 2013, 52, 12359.

(11) Plumb, K. Chem Eng Res Des 2005, 83, 730.

(12) McGlone, T. Briggs, N. E. B.; Clark, C. A.; Brown, C. J.; Sefcik, J.; Florence, A. J. Org Process Res Dev 2015, 19, 1186.

(13) Fitch, A. W.; Jian, H. B.; Ni, X. W. Chem Eng J 2005, 112, 197.

(14) Ni, X.; Brogan, G.; Struthers, A.; Bennett, D. C.; Wilson, S. F. Chem Eng Res Des 1998, 76,635 .

(15) Stonestreet, P.; Van der Veeken, P. M. J. Chem Eng Res Des 1999, 77, 671.

(16) Chew, C. M.; Ristic, R. I.; Reynolds, G. K.; Ooi, R. C. Chem Eng Sci 2004, 59, 1557.

(17) Mackley, M. R.; Stonestreet, P. Chem Eng Sci 1995, 50, 2211. 
(18) Ni, X.; Mackley, M. R.; Harvey, A. P.; Stonestreet, P.; Baird, M. H. I.; Rao, N. V. R. Chem Eng Res Des 2003, 81, 373.

(19) Zhao, L. H.; Raval, V.; Briggs, N. E. B.; Bhardwaj, R. M.; McGlone, T.; Oswald, I. D. H.; Florence, A. J. Crystengcomm 2014, 16, 5769.

(20) Ni, X. W. J Chem Technol Biot 1994, 59, 213.

(21) Ni, X.; Gough, P. Chem Eng Sci 1997, 52, 3209.

(22) Abbott, M. S. R.; Harvey, A. P.; Perez, G. V.; Theodorou, M. K. Interface Focus 2013, 3.

(23) Gough, P.; Ni, X. W.; Symes, K. C. J Chem Technol Biot 1997, 69, 321.

(24) Stonestreet, P.; Harvey, A. P. Chem Eng Res Des 2002, 80, 31.

(25) Zheng, M. Z.; Li, J.; Mackley, M. R.; Tao, J. J. Phys Fluids 2007, 19.

(26) Brown, C. J.; Ni, X. W. Crystengcomm 2012, 14, 2944.

(27) Chew, C. M.; Ristic, R. I.; Dennehy, R. D.; De Yoreo, J. J. Cryst Growth Des 2004, 4, 1045.

(28) Callahan, C. J.; Ni, X. W. Cryst Growth Des 2012, 12, 2525.

(29) Callahan, C. J.; Ni, X. W. Crystengcomm 2014, 16, 690.

(30) Brown, C. J.; Lee, Y. C.; Nagy, Z. K.; Ni, X. Crystengcomm 2014, 16, 8008.

(31) Ni, X. W.; Liao, A. T. Cryst Growth Des 2008, 8, 2875.

(32) Ni, X. W.; Liao, A. T. Chem Eng J 2010, 156, 226.

(33) Ni, X. W.; Valentine, A.; Liao, A. T.; Sermage, S. B. C.; Thomson, G. B.; Roberts, K. J. Cryst Growth Des 2004, 4, 1129.

(34) Baell, J.; Congreve, M.; Leeson, P.; Abad-Zapatero, C. Future Med Chem 2013, 5, 745.

(35) Danysz, W.; Parsons, C. G.; Bresink, I.; Quack, G. Drug News and Perspectives 1995, 8, 261.

(36) Sheldon, A. L.; Robinson, M. B. Neurochem Int 2007, 51, 333.

(37) Ono, T.; ter Horst, J. H.; Jansens, P. J. Cryst Growth Des 2004, 4, 465.

(38) Kitamura, M.; Ishizu, T. J Cryst Growth 2000, 209, 138.

(39) Ochsenbein, D. R.; Schorsch, S.; Vetter, T.; Mazzotti, M.; Morari, M. Ind Eng Chem Res 2014, 53, 9136.

(40) Scholl, J.; Lindenberg, C.; Vicum, L.; Brozio, J.; Mazzotti, M. Faraday Discuss 2007, 136, 247.

(41) Scholl, J.; Vicum, L.; Muller, M.; Mazzotti, M. Chem Eng Technol 2006, 29, 257.

(42) Cashell, C.; Corcoran, D.; Hodnett, B. K. J Cryst Growth 2004, 273, 258.

(43) Hatakka, H.; Alatalo, H.; Louhi-Kultanen, M.; Lassila, I.; Haeggstrom, E. Chem Eng Technol 2010, 33, 751.

(44) Kitamura, M. J Cryst Growth 1989, 96, 541.

(45) Alatalo, H.; Hatakka, H.; Kohonen, J.; Reinikainen, S. P.; Louhi-kultanen, M. Aiche J 2010, 56, 2063.

(46) Di Profio, G.; Curcio, E.; Ferraro, S.; Stabile, C.; Drioli, E. Cryst Growth Des 2009, 9 , 2179.

(47) Kee, N. C. S.; Tan, R. B. H.; Braatz, R. D. Cryst Growth Des 2009, 9, 3044.

(48) Qian, G.; Wu, Y. Y.; Yang, X. Y.; Duan, X. Z.; Zhou, X. G. J Cryst Growth 2013, 373, 78.

(49) Cornel, J.; Lindenberg, C.; Mazzotti, M. Cryst Growth Des 2009, 9, 243.

(50) Ma, C. Y.; Wang, X. Z.; Roberts, K. J. Adv Powder Technol 2007, 18, 707.

(51) Cashell, C.; Corcoran, D.; Hodnett, B. K. Cryst Growth Des 2005, 5, 593.

(52) Garti, N.; Zour, H. J Cryst Growth 1997, 172, 486.

(53) Kitamura, M.; Funahara, H. J Chem Eng Japan 1994, 27, 124. 
(54) Ferrari, E. S.; Davey, R. J. Cryst Growth Des 2004, 4, 1061.

(55) Scholl, J.; Bonalumi, D.; Vicum, L.; Mazzotti, M.; Muller, M. Cryst Growth Des 2006, 6, 881.

(56) Borissova, A.; Khan, S.; Mahmud, T.; Roberts, K. J.; Andrews, J.; Dallin, P.; Chen, Z. P.; Morris, J. Cryst Growth Des 2009, 9, 692.

(57) Liang, K. P.; White, G.; Wilkinson, D.; Ford, L. J.; Roberts, K. J.; Wood, W. M. L. Ind Eng Chem Res 2004, 43, 1227.

(58) Khan, S.; Ma, C. Y.; Mahmud, T.; Penchev, R. L. Y.; Roberts, K. J.; Morris, J.; Ozkan, L.; White, G.; Grieve, B.; Hall, A.; Buser, P.; Gibson, N.; Keller, P.; Shuttleworth, P.; Price, C. J. Org Process Res Dev 2011, 15, 540.

(59) Grier, J. S.; Pines, S. H.; Google Patents: 1968.

(60) Roelands, C. P. M.; ter Horst, J. H.; Kramer, H. J. M.; Jansens, P. J. J Cryst Growth 2005, 275, E1389.

(61) Alvarez, A. J.; Myerson, A. S. Cryst Growth Des 2010, 10, 2219.

(62) Lai, T. T. C.; Ferguson, S.; Palmer, L.; Trout, B. L.; Myerson, A. S. Org Process Res Dev 2014, 18, 1382.

(63) Hirayama, N.; Shirahata, K.; Ohashi, Y.; Sasada, Y. B Chem Soc Jpn 1980, 53, 30.

(64) Hirokawa, S. Acta Crystallogr 1955, 8, 637.

(65) Levenspiel, O. Chemical Reaction Engineering 3rd ed.; Wiley: New York, USA, 1999.

(66) Muller-Steinhagen, H. Heat Transfer Eng 2011, 32, 1.

(67) Zhao, X.; Chen, X. D. Heat Transfer Eng 2013, 34, 719.

(68) Eder, R. J. P.; Schmitt, E. K.; Grill, J.; Radl, S.; Gruber-Woelfler, H.; Khinast, J. G. Cryst Res Technol 2011, 46, 227.

(69) Al Nasser, W. N.; Pitt, K.; Hounslow, M. J.; Salman, A. D. Powder Technol 2013, 238, 151.

(70) Majumder, A.; Nagy, Z. K. Cryst Growth Des 2015, 15, 1129.

(71) Beckmann, W. Org Process Res Dev 2000, 4, 372.

(72) Donnet, M.; Bowen, P.; Jongen, N.; Lemaitre, J.; Hofmann, H. Langmuir 2005, $21,100$.

(73) Woo, X. Y.; Tan, R. B. H.; Braatz, R. D. Crystengcomm 2011, 13, 2006.

(74) Beckmann, W.; Nickisch, K.; Budde, U. Org Process Res Dev 1998, 2, 298.

(75) Narducci, O.; Jones, A. G.; Kougoulos, E. Org Process Res Dev 2011, 15, 974.

(76) Aamir, E.; Nagy, Z. K.; Rielly, C. D.; Kleinert, T.; Judat, B. Ind Eng Chem Res 2009, 48, 8575.

(77) Costa, C. B. B.; Maciel, M. R. W.; Maciel, R. Comput Chem Eng 2007, 31, 206.

(78) Lindenberg, C.; Krattli, M.; Cornel, J.; Mazzotti, M.; Brozio, J. Cryst Growth Des 2009, 9 , 1124.

(79) Nagy, Z. K.; Braatz, R. D. Annu Rev Chem Biomol 2012, 3, 55.

(80) Ono, T.; Kramer, H. J. M.; ter Horst, J. H.; Jansens, P. J. Cryst Growth Des 2004, 4, 1161. 